\title{
Infrared Inspection Method for Actively Cooled Panels
}

\author{
Brett K. Hauber \\ United States Air Force \\ ASC/ENFP
}

Wright Patterson AFB, OH 45433

\begin{abstract}
This paper discusses a new technique for determining the integrity of Actively Cooled Thermal Protection Systems designed for testing in high heat flux environments. These components, which use common as well as leading edge materials, are expensive and time consuming to fabricate. Using commercial thermography systems, a technique has been developed to detect blocked passages that would effect the performance and in many cases the survivability of the components. This not only avoids wasted test time but also provides a new capability for accepting manufactured systems. The technique is applied before, during and after testing as a damage assessment tool.

The thermography system consists of a camera, video recorder, and a $\mathrm{PC}$ for data processing and viewing. The camera can detect the spatial and temporal distribution of infrared radiation emanating from the surface of a specimen. This information, together with material property data, can be used to calculate and display surface temperature distribution. The images are processed to provide false-color contour plots.
\end{abstract}

\section{INTRODUCTION}

One of the key technologies in the development of hypersonic scramjet propulsion systems is active thermal protection. Active thermal protection can take several forms: heat pipes, transpiration cooling, or regenerative cooling. For the National Aerospace Plane Program (NASP), considerable effort was expended to design, fabricate and test hydrogen cooled (regeneratively cooled) panels. The primary materials of choice for this program were Haynes 188 (H188), a cobalt based alloy; NARloy-Z, a copper based alloy; and a Mo-Re alloy which did not make it into test. The need to develop an IR based inspection method began with the testing of $\mathrm{H} 188$ panels in the Wright Laboratories Mini Hydrogen Facility.

The first shipment of Haynes 188 (H188) $1 \times 4$ inch test articles, fabricated by Allison Engine Co., was received in early April 1994. Prior to testing, the articles where inspected using $50 \mathrm{MHz}$ ultrasonics with particular attention paid to the bond lines. At the time, channel blockage was not considered likely, due to the fabrication methods used. Furthermore, specimen geometry precluded use of X-ray, Cat-Scan inspection, or any other method relying on through penetration of a signal, methods that would normally be used to find such a flaw (see figure 1). Following inspection, the first of five specimens was instrumented and testing began. After several test cycles, most of which were below $50 \%$ of design test conditions, the article failed. Visual examination of the aricle revealed several very tight cracks in the surface along with discoloration due to overheating. Eventually, destructive investigation determined that $\mathrm{Al}$ and $\mathrm{Ti}$ oxide, used during fabrication as a braze stop-off, partially or totally blocked most of the internal channels. This blockage was also confined to the interface between manifold and heat exchanger (HEX). Ideally this material should have been removed by ultrasonic (UT) cleaning following the final braze operation; however, the cleaning methods used by Allison clearly were not totally effective. In fact, upon destructive evaluation, more than $90 \%$ of the channels contained residual stop-off, several of which may have been completely blocked during the test. At this point it was obvious that a method would have to be found or developed which could detect blockage undetectable by other methods. Without such an inspection technique, successful testing of the remaining four test articles was doubtful. To that end, a method was developed using IR Thermography by which 


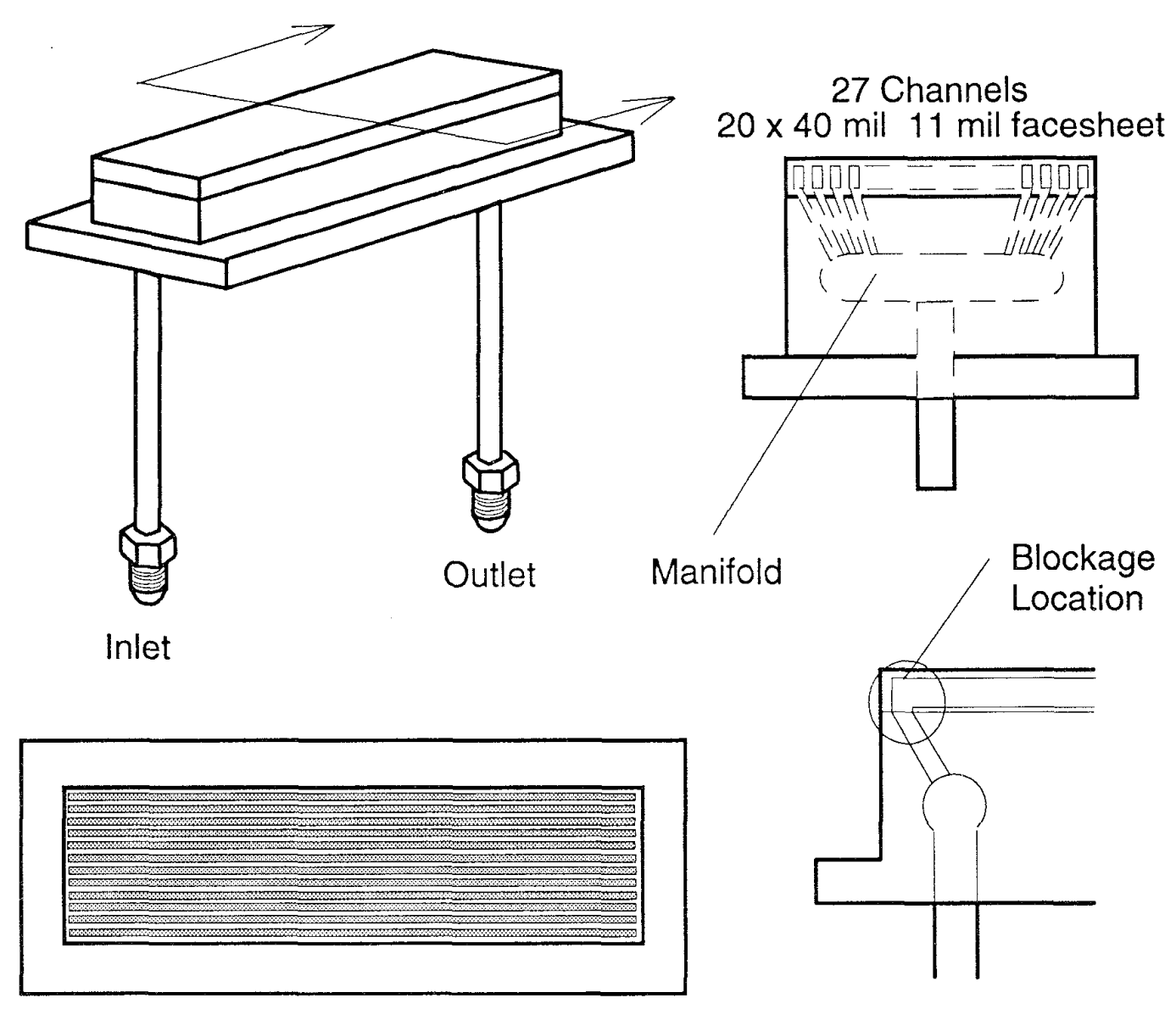

Figure 1. 1"x4" Specimen Geometry

blockage could be visualized. In addition, a method was also developed that could clear the stop-off from the channels.

The final IR inspection process involved heating the specimen internally with a constant supply of high pressure (110 psi) steam. Steam was introduced into either manifold line and allowed to discharge to atmospheric pressure from the other. Generally, the inspection was done in both directions. Depending upon the material, a thermal image was captured either during the initial transient heat up (NARloy-Z) or after the test article had come to thermal steady state (H188).

\section{INSPECTION PROCESS}

\section{Inspection Development}

Initial method development was performed on the failed test specimen. Though cracked, the very tight nature of the cracks prevented low pressure fluids from leaking to the surface. This specimen was selected for initial development for two reasons. First, heat tinting and cracking of the test article facesheet during testing indicated that several channels were starved of coolant, the most likely cause of which was foreign matter in the channels or manifold. This gave us a specimen with known or suspected defects to find. If a second specimen had been used and inspection results had been negative, there would have been no way to determine if the inspection was unsuccessful or if the specimen was flaw free without destroying the article. We intended to destructively inspect the failed article, providing 
definite information on channel obstructions. Second, a method was needed that would support the visual observations indicating blocked channels to help guide eventual destructive inspection.

Initial inspections were performed with facility steam at approximately $10 \mathrm{psi}(240 \mathrm{~F})$. The inspection began by cleaning and then coating the surface of the test article with a thin coating of high emmissivity (.95) paint. The article was then connected to the steam line just down stream of an electric solenoid controlled valve allowing instantaneous on/off control of the steam. The inspection was performed by instantly opening the valve and recording the transient and steady state thermal responses of the panel face sheet. Both transient and steady state images were recorded on video tape using a VCR and as still images stored on a computer hard drive. Images were made with both hot water (steam condensate between inspections) and steam. After inspecting the article in one direction, the connections were reversed and the inspection repeated. This step was necessary to determine which channels were blocked, as the image from a single inspection could result from two different situations: either most of the channels were blocked or few of the channels were blocked. By rotating the test article, clear channels were obvious.

With the basic inspection procedures developed the method was refined to provide better detail. The use of high temperature water was dropped since it necessitated capturing an image as the article heated. Steam pressure was increased to $110 \mathrm{psi}$. This produced higher temperature steam, higher pressure drop through the articles, and higher temperature gradients from inlet to outlet. The solenoid controlled valve was determined to be unnecessary and was replaced with a simple hand operated valve.

\section{Final Process Procedure}

The surface to be viewed is thoroughly cleaned and a black emmisivity paint is applied. In this case it was a common black spray paint with a known emmisivity. The article is then attached to a high pressure (110 psi) steam supply line and a steam discharge line. The discharge line directs the continuous flow of steam outside of the inspection area. Note: there are no obstructions or valves down stream of the test article. To do so would decrease steam mass flow through the test article and associated pressure drop, limiting resolution. With the article installed, the camera, computer, and VCR are setup to view and record the surface response (figure 2). Just prior to inspection, condensate is cleared from the steam line through the article. In low conductivity materials the inspection can begin as soon as steam begins to flow through the article. However, with high conductivity materials, the steam valve must be closed for a short period of time to allow the article to cool somewhat since the image obtained on these materials can only be captured during the heat up transient. Finally, the article is reversed in the setup and the inspection repeated. Comparison of the resulting images clearly shows areas of reduced flow.

\section{INSPECTION RESULTS}

Throughout the development of this inspection method, hot water, steam and high pressure steam were tried as heat sources. Of these, the least effective was water. Only transient images contained meaningful data and, though the images were good, they provided less than a complete inspection. The properties of high and low pressure steam proved to be much better suited to the inspection. Most important to the inspection were gas expansion effects.

Unlike water, steam temperature drops as pressure drops with expansion through the article (figure 3). In any given channel three possibilities controlled expansion/pressure drop and resultant temperature, no blockage, down stream blockage, or up stream blockage. Down stream of an obstruction there was an immediate reduction in pressure and as a result, decrease in surface temperature. If heavily blocked, a channel would be cool from inlet to outlet, a result of pressure downstream of the blockage expanding to nearly the outlet manifold pressure. If only slightly blocked, expansion was not as complete and further measurable temperature reduction was observed as the steam further expanded to outlet manifold pressure. In both these cases, steam in the blocked channel is a heat sink, carrying away heat that conducts to the channel from adjacent channels. Upstream of a blockage, pressure remained high. Like flow downstream of a blockage, surface temperature depended upon the severity of blockage. Major blockage resulted in elevated temperatures from end to end. Expansion through a clear channel was constant and resulted in uniform reduction of surface temperature from inlet to outlet. 


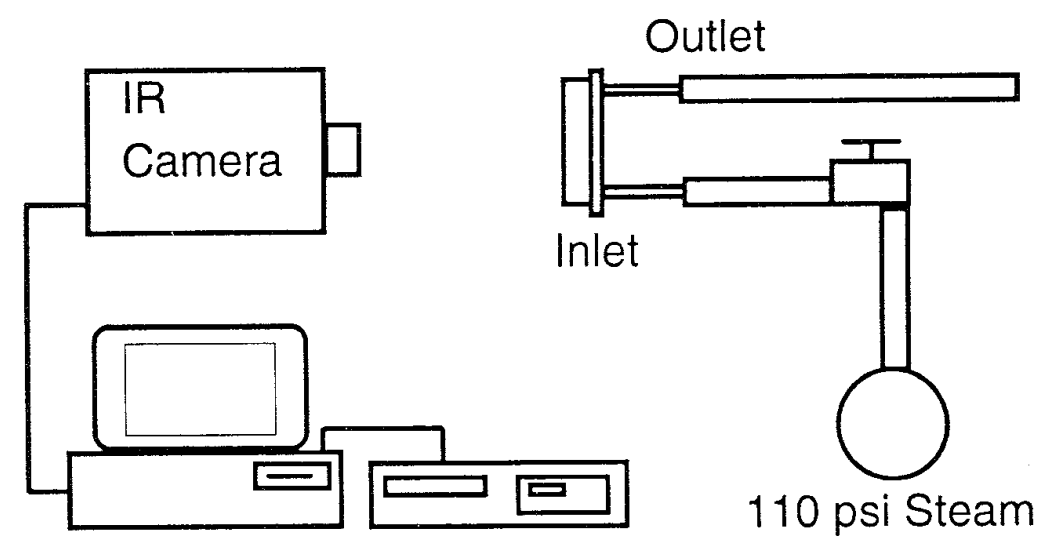

Figure 2. System Schematic

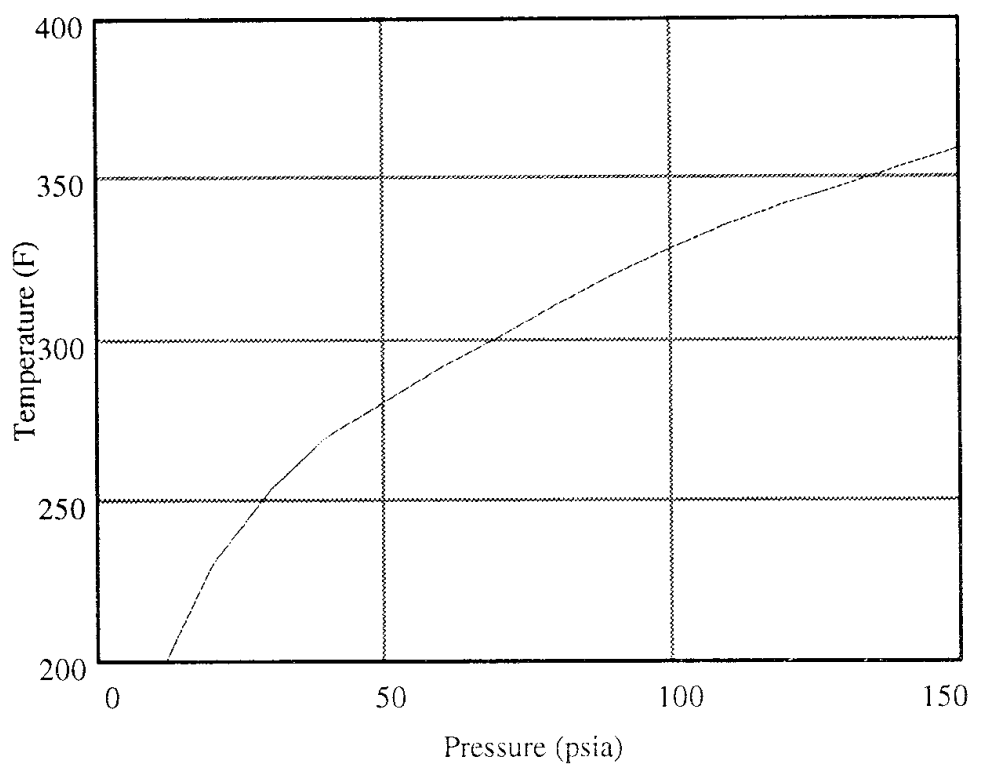

Figure 3. Temperature of Saturated Steam (1)

An additional possibility was complete blockage of a channel. It is unclear without thermal analysis what effect total blockage would have on surface temperature. It would seem that without flow in a channel, heat could neither be added nor carried away in that channel by the steam. This would leave as the only thermal paths, conduction from surrounding channels and free convection from the surface. Whether free convection would be enough to result in even a slight and measurable temperature reduction over the blocked channel is unknown. Obviously it would depend upon the surface temperature, material conductivity and free convection heat transfer coefficient, as well as other physical and geometrical considerations. However, given normal values of free convection heat transfer coefficients it seems likely that a completely blocked channel would not be easily detectable in a steady state image. It might be detectable, however, in the initial transient.

One slight disadvantage of low pressure steam was a tendency for what appeared to be condensation and 
trapping of water in the channels. This gave the image an animated appearance that reduced image resolution. The switch to high pressure steam (110 psi) appeared to solve the problem of condensation within the article and it also improved resolution. The higher flow rates associated with high pressure steam produced higher pressure drop through the articles and higher temperature gradients from inlet to outlet.

\section{Water}

As stated previously, water was not the best fluid for internally heating the test articles. When using water, even in low conductivity H188 (7.7 BTU/hr-ft-F@300 F), the only meaningful image was a transient image; however, images were produced. Figure 4 shows one of the initial images produced on the failed test article using water. As can be seen, there is relatively good agreement between the IR image and the heat tinting present on the face of the article (Figure 5). Major areas of blockage show up quite well, though other minor areas do not.

\section{Steam}

Figure 6 shows the same article inspected with low pressure steam. Comparing this image to Figure 4 illustrates the added resolution present when steam is used. In addition to the two or three areas of blockage visible with water, additional areas of lesser restrictions are seen. It is, however, harder to interpret and compare steam images to figure 5 than the images produced with water. With water, regardless of blockage location, temperature of any channel during the transient is controlled by the flow rate of water passing through the channel. Channels flowing less water remain cooler longer during the transient temperature rise. However, once the article reaches temperature, the temperature affect due to blockage disappears. With steam, the image is effected by the location of blockage. Some areas run cooler, indicating upstream blockage; others run hotter, indicating downstream blockage. An example of this effect can be seen in figures 7 and 8 . Both are of the same test article but with seam flow in opposite directions. Three groups of channels are blocked in this article. In figure 7, how is from right to left with blockage at the steam inlet. Down stream of the blockage the channels appear cooler than the surrounding surface. In figure 8 flow is from left to right. Here blockage is at the steam outlet and the channels run hot. Note that if the inspection is performed in only a single direction determination of which channels are blocked is not obvious. For example, examination of figure 7 alone could be interpreted to indicate that the three groups of channels are the only free flowing channels, the others being blocked at the outlet. Truly blocked channels are indicated when using both images, by consistent indication of blockage location. In this case, both images indicate that the three groups of channels are blocked at the right end of the article.

Figures 9 and 10 compare the results for the same article using low and high pressure steam. Here, high pressure steam offers a resolution advantage over low pressure steam. Where with low pressure steam, temperature gradients through the article are approximately $15 \mathrm{~F}$ in this case, temperature gradients with high pressure steam are nearly $35 \mathrm{~F}$. These larger temperature gradients, due to larger pressure gradients, result in the enhanced resolution that can be seen in figure 10 .

A final image (figure 11) shows the result after the article has been cleared of virtually all blockage, although some channels still show slight blockage. Note that there are two indications that the article has indeed been cleared of blockage. First, the image is uniform across the width of the test article. Second, the temperature gradient from inlet to outlet is roughly $15 \mathrm{~F}$ vs $35 \mathrm{~F}$ for a blocked article.

\section{NARloy-Z}

In addition to the inspections performed on $\mathrm{H}: 88$ test articles, inspections were also made of NARloy- $Z$ aricles. The main differences between then are as follow. Characteristics of the H188 test articles were low conductivity, thin face sheet $(011 \mathrm{in})$, heavy blockage, and small channel geomerry $6.040 \mathrm{~h} \times .020 \mathrm{w}$ in). NARloy 2 article characteristics were: high conductivity $(205 \mathrm{Br}$ J/Lhr-F), thicker face sheet $(.017 \mathrm{~m})$, little or no blockage and smaller channel dimensions $(.020 \mathrm{~h} \times .026 \mathrm{w}$ in)

The differences of the NARloy-Z articles compare to the 1188 articles resulted in more difficult inspections. Exh with high pressure steam, detalled images were ony detectable in the first two to thes seconds of the trinsient temperature rise. Beyond this time frame suttace temperawe across the face of the aricle hecame a constant. This behavior was even twe in the one NARloy$Z$ article known to contain several partially blocked passages. Ironically, it is probably the high quality of these articles that makes it hard to conclude whether the inspection will work on an article with these characteristics. 
Had some of these articles been severely blocked, far more probabiy would have been learned about the inspection method application to high conductivity materials.

\section{CONCLUSIONS}

Based upon correlation of inspection results with surface distress on the failed article as well as destructive inspection results, the application of IR Thermography as an inspection method for detecting channel blockage in cooled panels has merit. Its application to cooled structures with small closely spaced channels has been demonstrated to work for low conductivity materials. However, given the focus of the inspection development and inspections themselves, the results were necessarily qualitative. No effort was made to quantify the capabilities of the inspection method. Efforts in this case were only to provide a measure of confidence that articles were free of blockage prior to testing.

Use with higher conductivity materials such as those used in rocket thrust chambers where copper alloys are ideally suited to the application remains questionable. Results with NARloy-Z, a common rocket chamber material, were limited, primarily because none of the articles provided significant blockage with which to test the inspection.

Further development of this technique requires as a minimum the following tasks. First: a systematic inspection program using specimens designed for development of the inspection is necessary. These specimens should encompass a range of materials, external geometries, internal channel geometries and combinations and degrees of blockage. Use of other gases and pressures should be explored. The objectives of the development should be to determine the sensitivity of the inspection and the influence of the above parameters on the sensitivity. Second: preand post-test analyses should be performed for each test to thoroughly understand the physical behavior of the specimen and fluid. Third: if this inspection technique is to be used to inspect critical components, specific specimens incorporating significant features of the parts to be inspected must be fabricated. Using these specimens, probabilities of detection and confidence levels must be developed for the defect sizes of interest.

\section{ACKNOWLEDGMENTS}

I would like to acknowledge the active participation and technical advice of Mr. Gary Clinehens. Mr. Clinehens provided IR Thermography expertise and advice based upon general knowledge and experience that made this program a success. He also performed the inspections and was responsible for setting up, running and making improvements to the procedure. I must also thank Mr. Gene Maddux whose generosity in providing Mr. Clinehens services made this program possible.

Bibliography

\section{Marks' Standard Handbook for Mechanical Engineers, 8th Edition, McGraw Hill.}




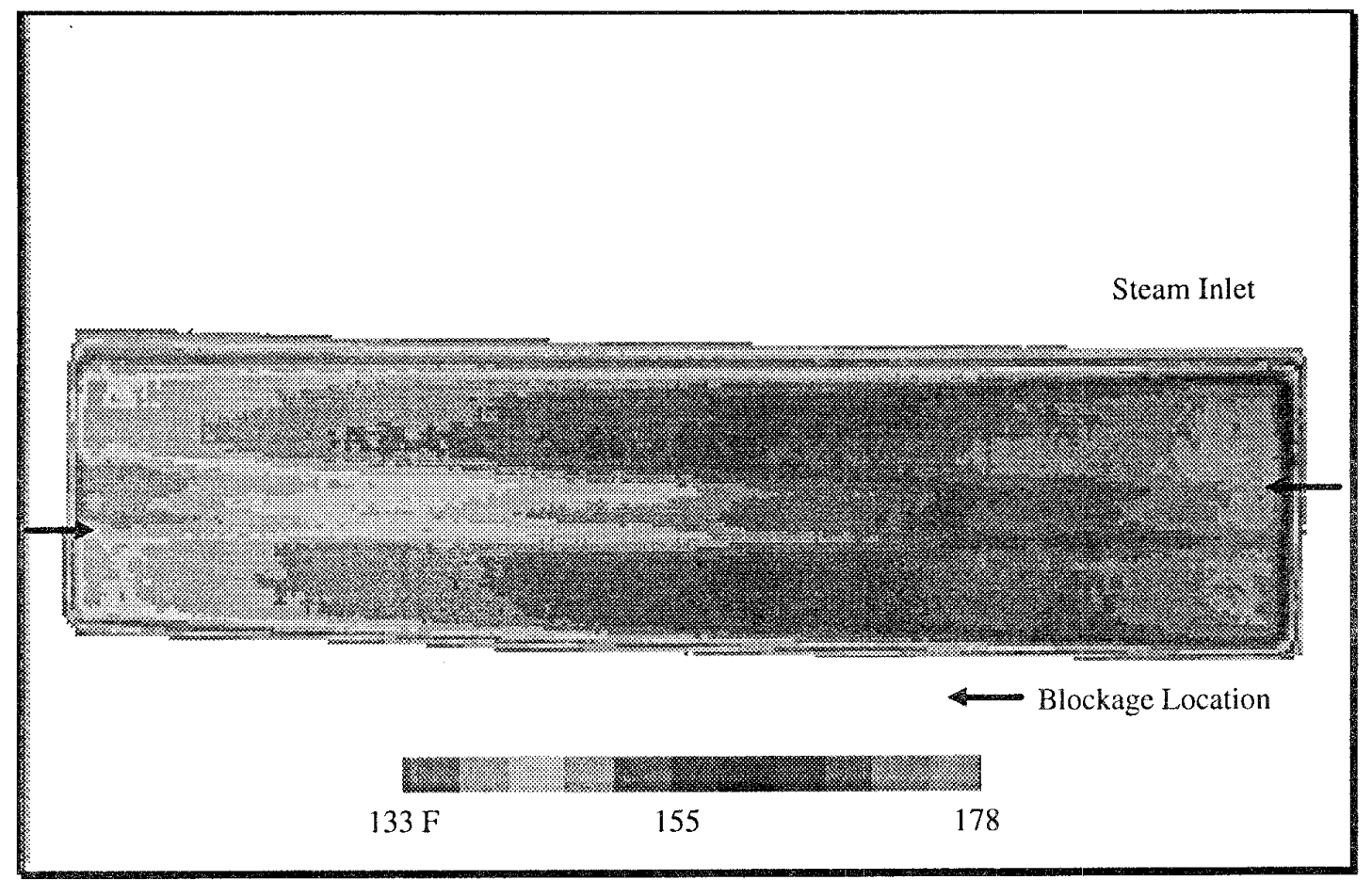

Figure 4. Surface Temperature Profile - Water Inspection Image of Failed Test Acticle (SN 615-041-02)

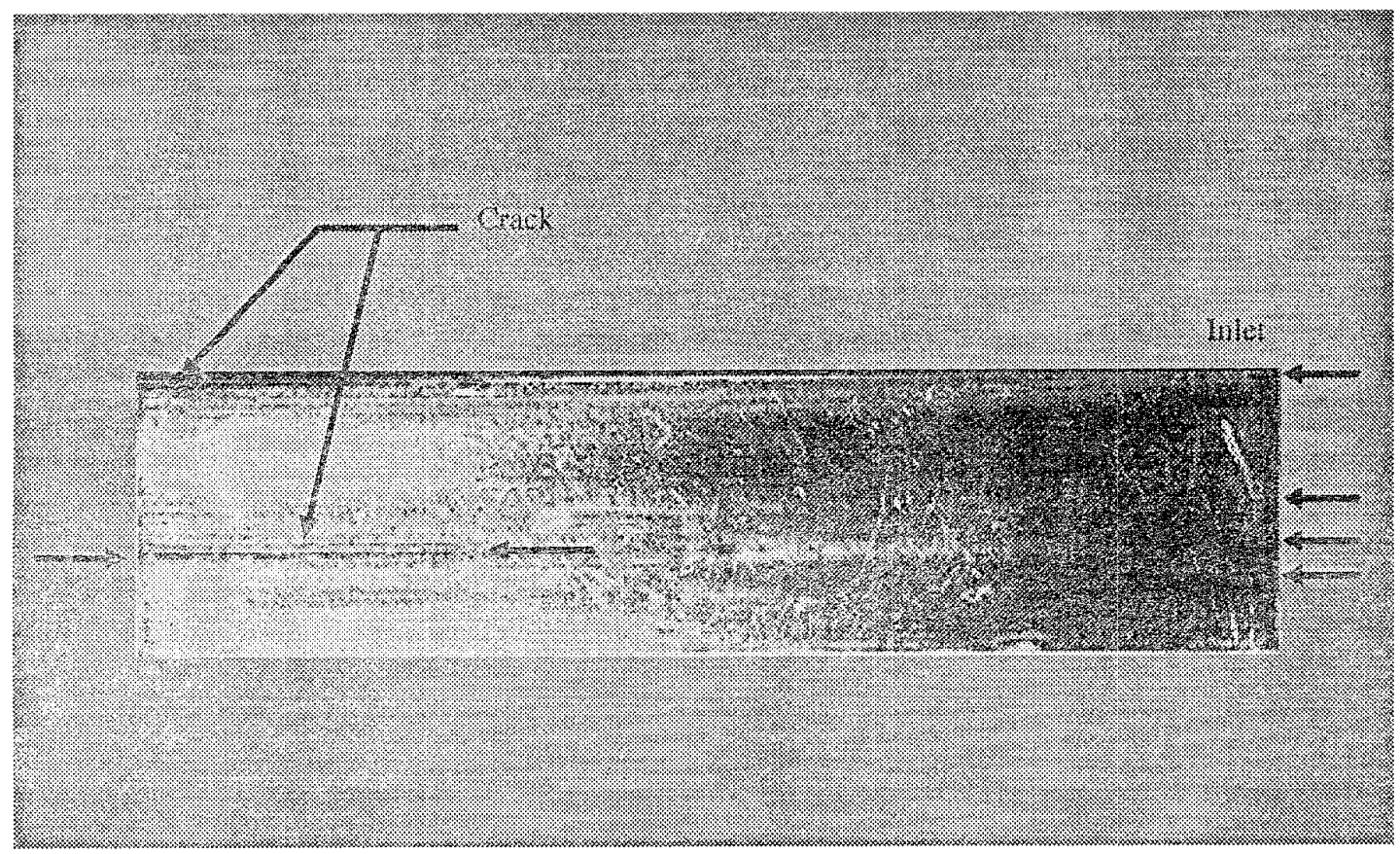

Figure 5. Photograph of Surface Discoloration and Distress (SN 615-0410-02) 


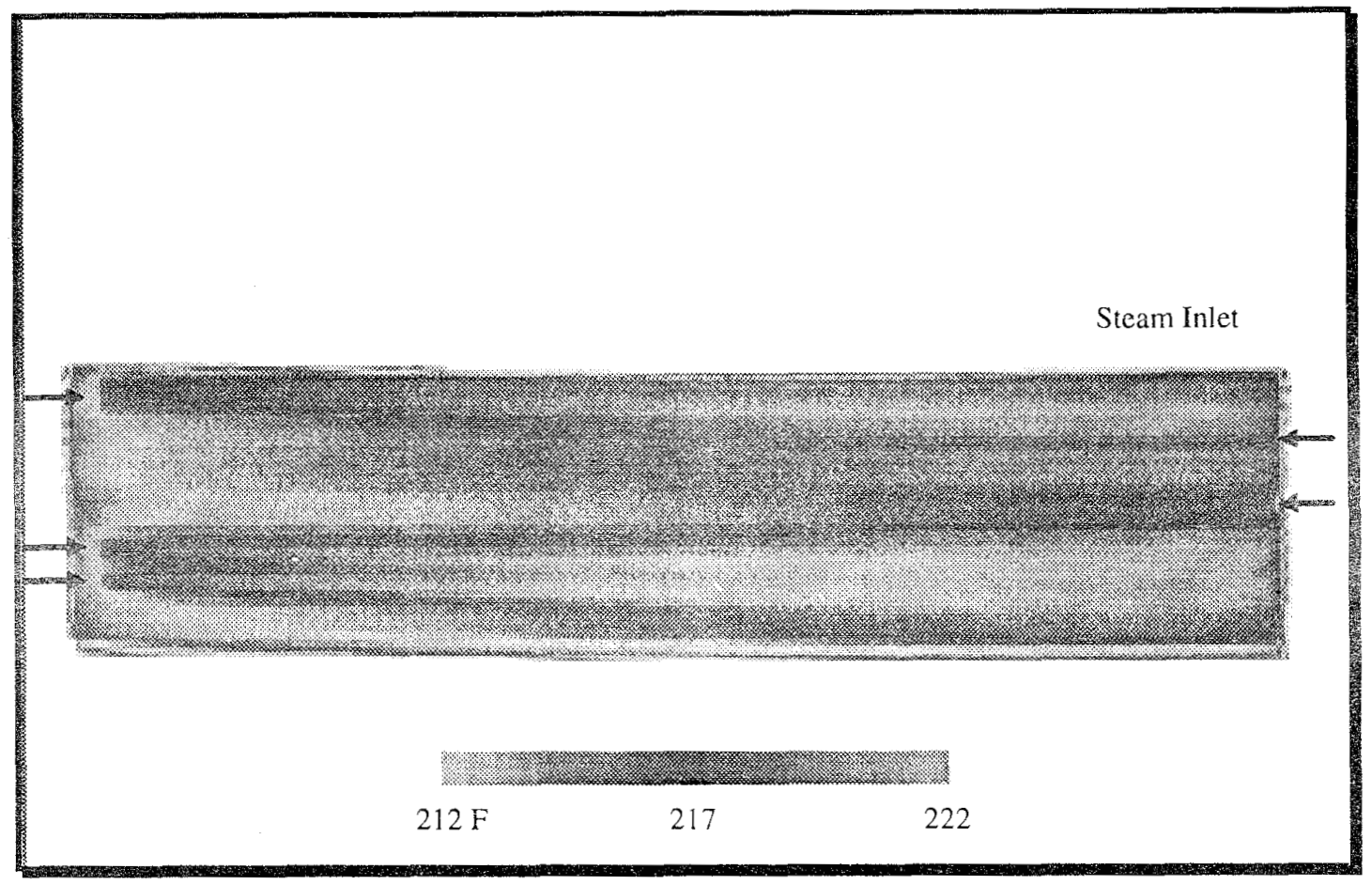

Figure 6. Surface Temperature Profile - Low Pressure Steam Inspection (SN 615-041-02) 


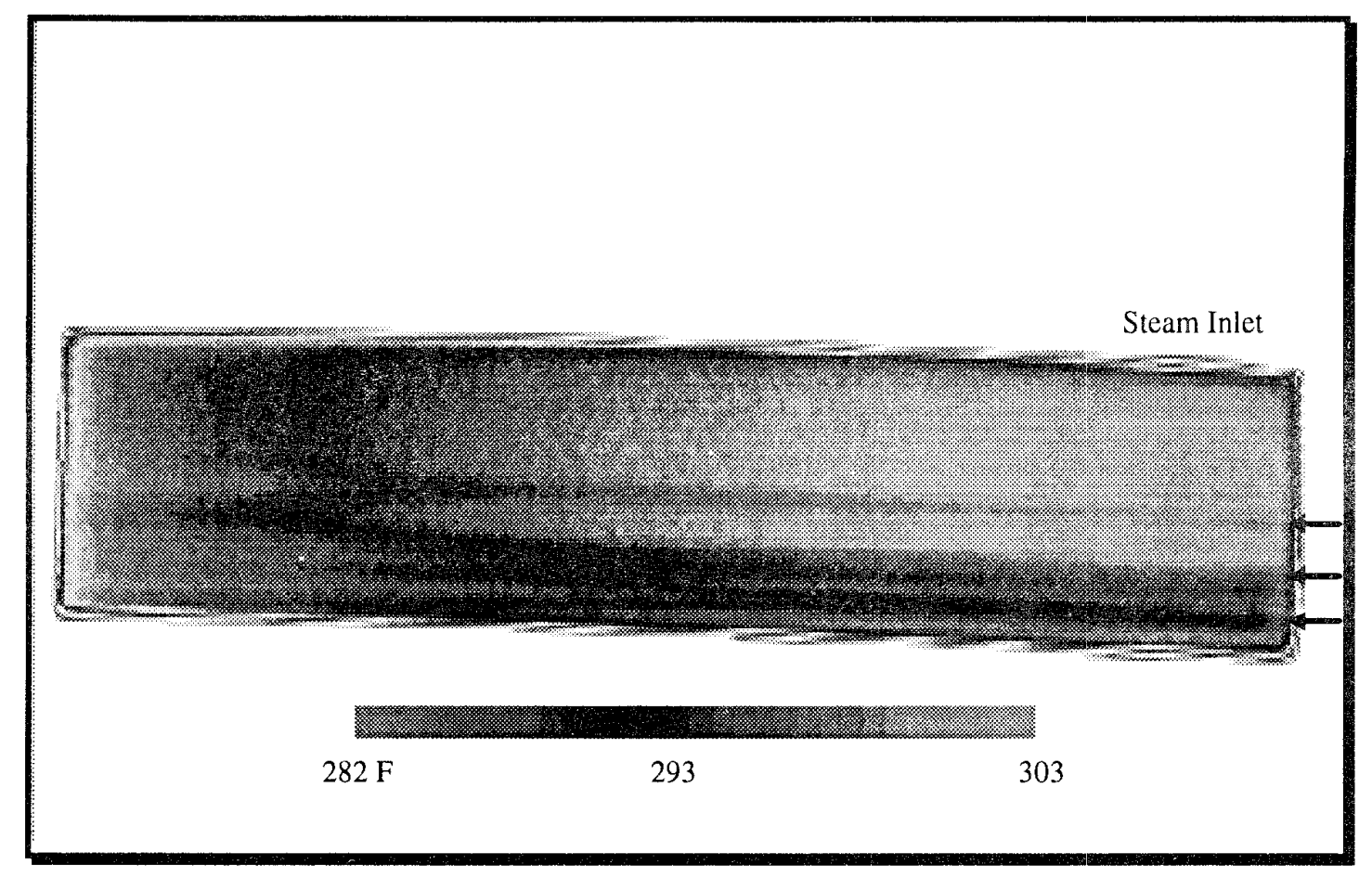

Figure 7. High Pressure Steam Image - (SN615-041-04)

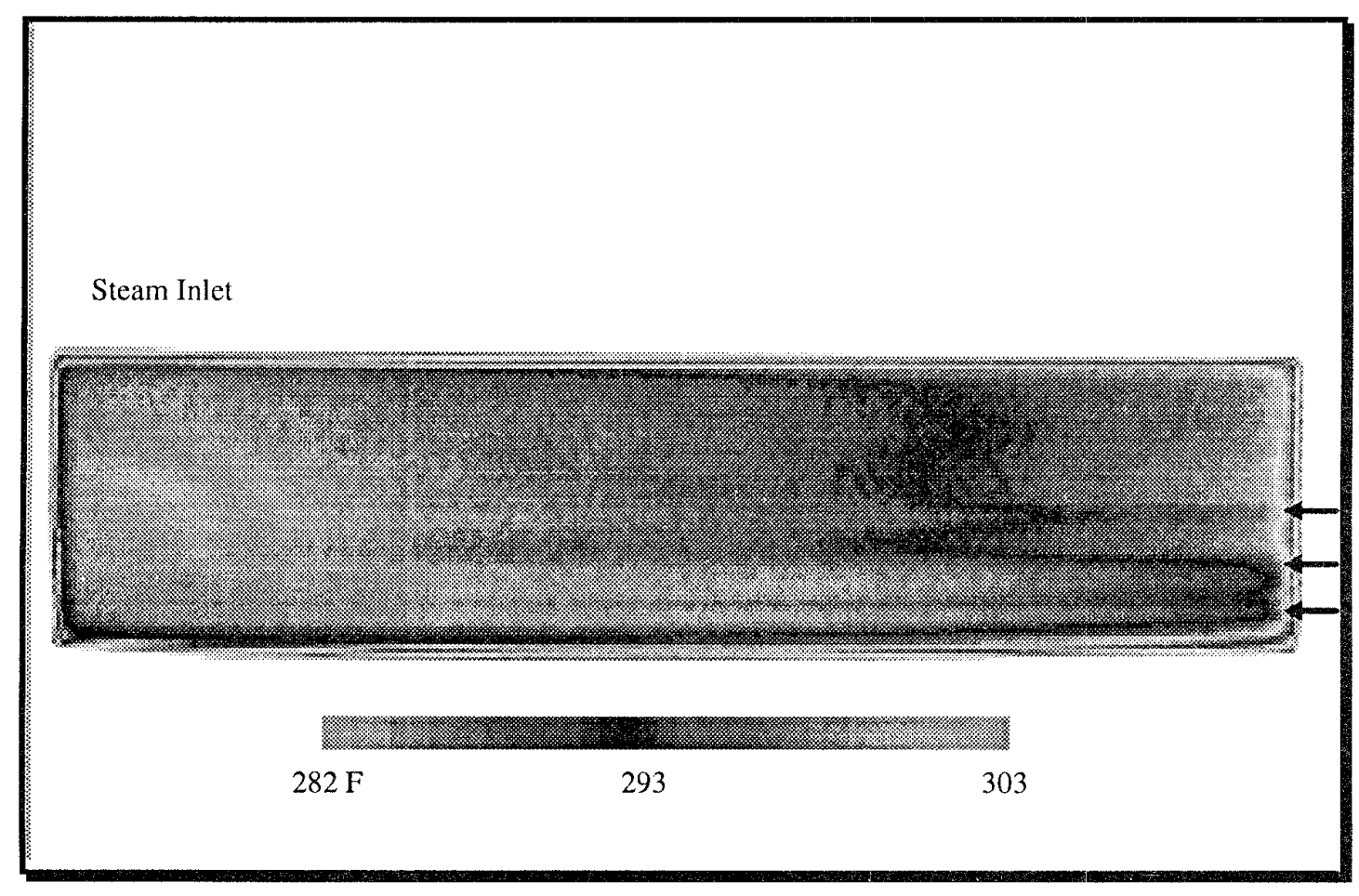

Figure 8. High Pressure Steam Image (Reverse Flow Direction) - (SN615-041-04) 


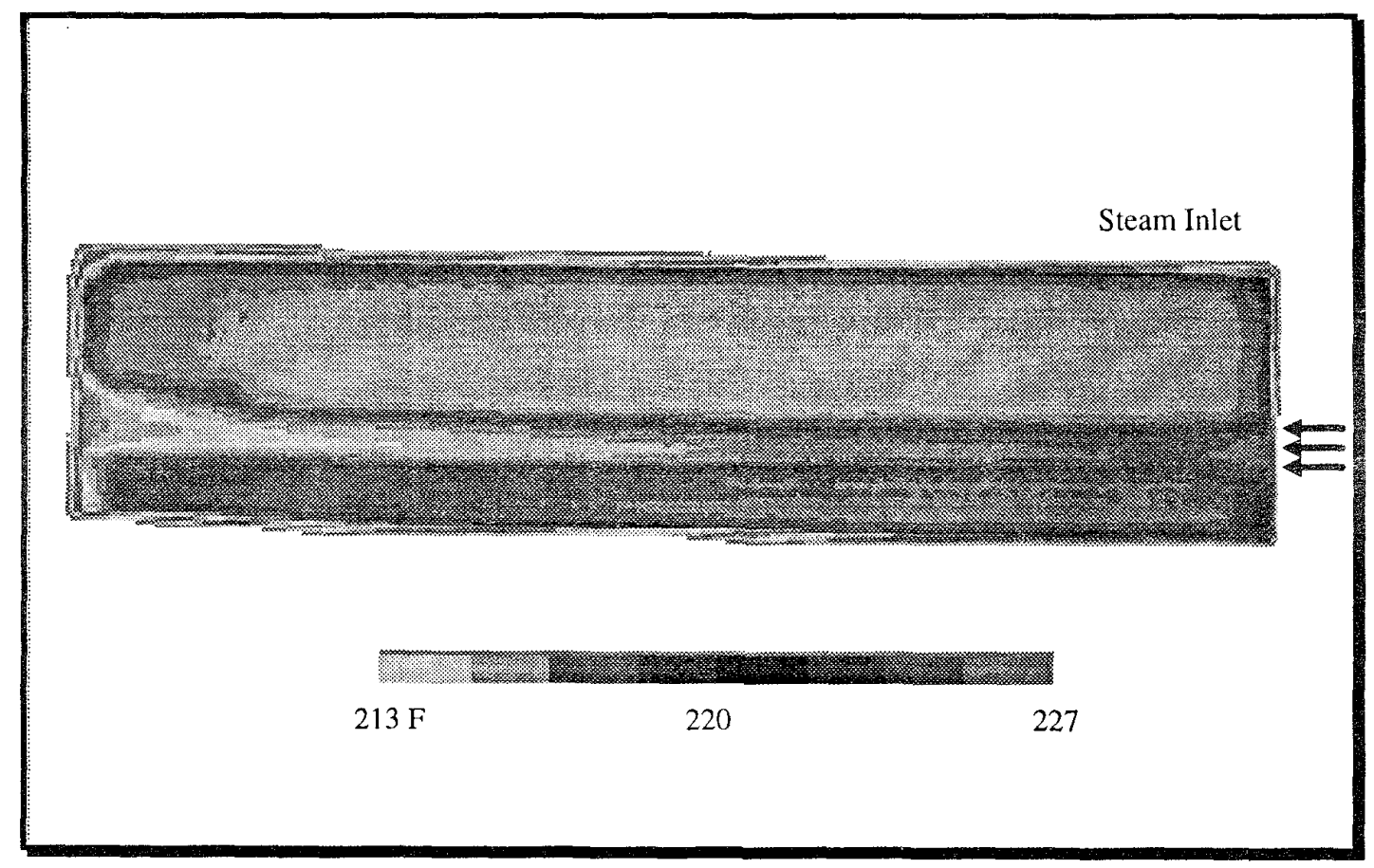

Figure 9. Low Pressure Steam Image - (SN 615-041-01)

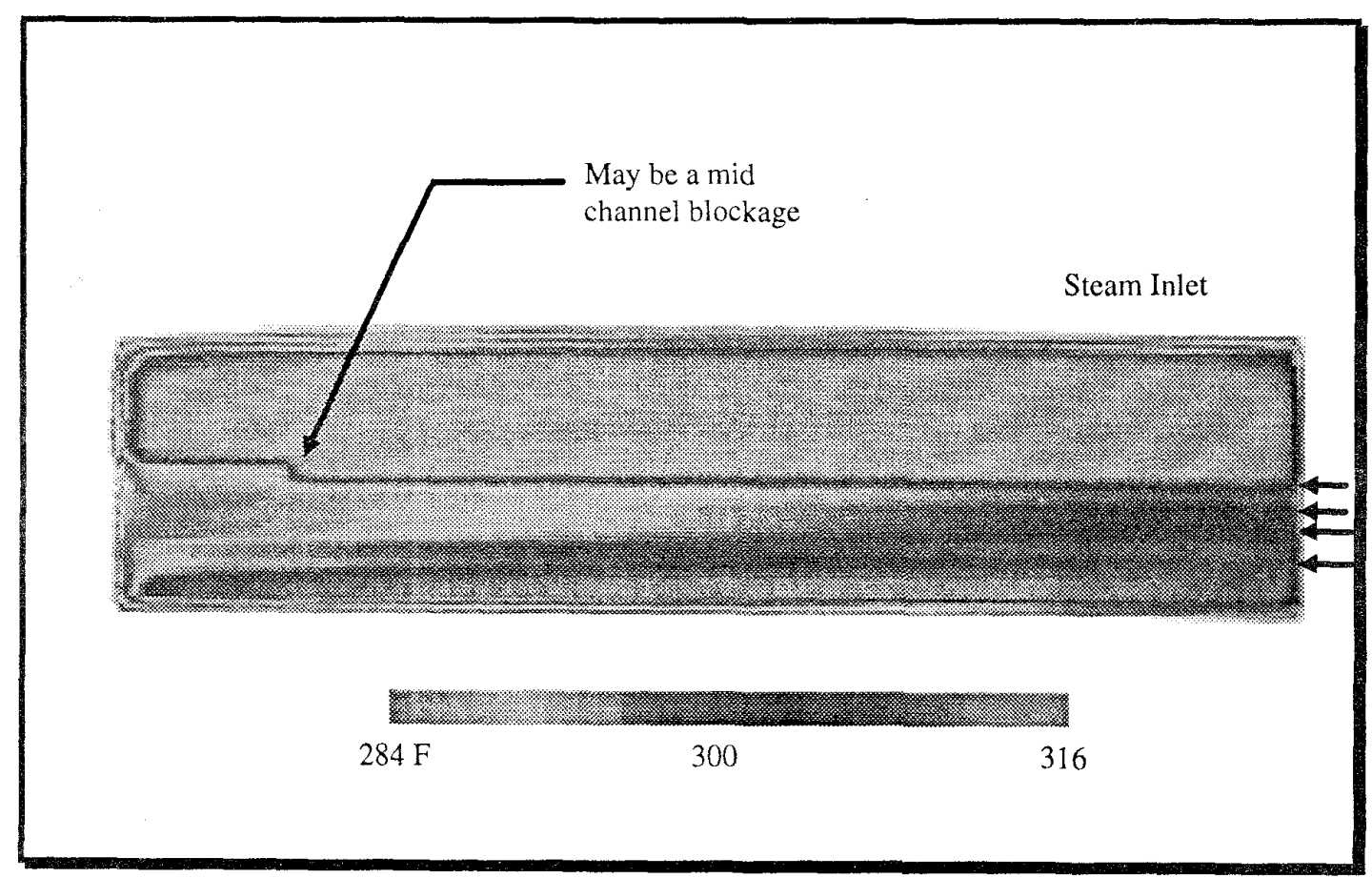

Figure 10. High Pressure Steam Image - (SN 615-041-01) 


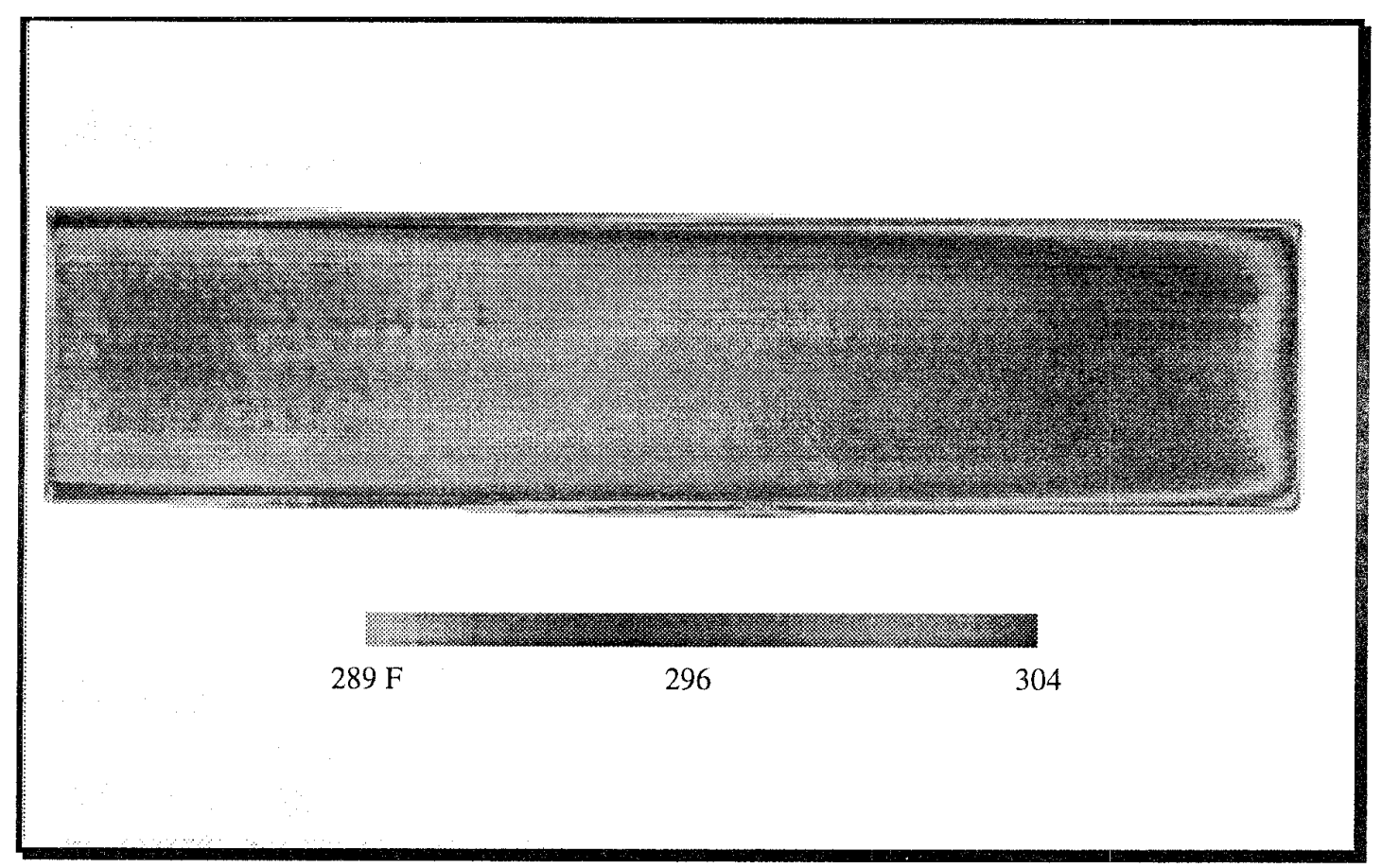

Figure 11. High Pressure Steam Image - (SN 641-001-01)

15.11 